\title{
Preconception carrier screening for multiple disorders: evaluation of a screening offer in a Dutch founder population
}

\author{
Inge B. Mathijssen ${ }^{1} \cdot$ Kim C.A. Holtkamp ${ }^{2,3}$ - Cecile P.E. Ottenheim ${ }^{1}$ - Janneke M.C. van Eeten-Nijman ${ }^{1}$. \\ Phillis Lakeman ${ }^{1} \cdot$ Hanne Meijers-Heijboer ${ }^{1,2} \cdot$ Merel C. van Maarle ${ }^{1} \cdot$ Lidewij Henneman $^{2,3}$
}

Received: 29 June 2017 / Revised: 8 October 2017 / Accepted: 13 November 2017 / Published online: 10 January 2018

(c) European Society of Human Genetics 2018

\begin{abstract}
Technological developments have enabled carrier screening for multiple disorders. This study evaluated experiences with a preconception carrier screening offer for four recessive disorders in a Dutch founder population. Questionnaires were completed by 182 attendees pretesting and posttesting and by 137 non-attendees. Semistructured interviews were conducted with seven of the eight carrier couples. Attendees were mainly informed about the existence of screening by friends/ colleagues $(49 \%)$ and family members $(44 \%)$. Familiarity with the genetic disorders was high. Knowledge after counseling increased $(p<0.001)$; however, still $9 \%$, compared to $29 \%$ before counseling, wrongly mentioned an increased risk of having an affected child if both parents are carriers of different disorders. Most attendees (97\%) recalled their test results correctly, but two couples reported being carrier of another disorder than reported. Overall, $63 \%$ felt worried while waiting for results but anxiety levels returned to normal afterwards. In all, 2/39 (5\%) carriers felt less healthy. Screened individuals were very satisfied; they did not regret testing (97\%) and would recommend testing to others (97\%). The majority (94\%) stated that couples should always have a pretest consultation, preferably by a genetic counselor rather than their general practitioner (83\%). All carrier couples made reproductive decisions based on their results. Main reason for non-attendance was unawareness of the screening offer. With expanded carrier screening, adequately informing couples pretest and posttesting is of foremost importance. Close influencers (family/friends) can be used to raise awareness of a screening offer. Our findings provide lessons for the implementation of expanded carrier screening panels in other communities and other settings.
\end{abstract}

\section{Introduction}

Genetic carrier screening for multiple genetic disorders is becoming widely available. Preconception carrier screening aims to benefit prospective parents by enabling carrier couples at increased risk of having affected offspring to

Electronic supplementary material The online version of this article (https://doi.org/10.1038/s41431-017-0056-4) contains supplementary material, which is available to authorized users.

Inge B. Mathijssen

i.b.mathijssen@amc.uva.nl

1 Department of Clinical Genetics, Academic Medical Center, Amsterdam, The Netherlands

2 Department of Clinical Genetics, VU University Medical Center, Amsterdam, The Netherlands

3 Amsterdam Public Health Research Institute, VU University Medical Center, Amsterdam, The Netherlands make informed reproductive choices. These include refraining from having children, preimplantation genetic diagnosis (PGD), and prenatal diagnosis (PND). In the past decades, carrier screening was mainly performed in specific high-risk (sub)populations and for relatively common recessive disorders associated with significant morbidity and reduced life expectancy [1]. Technological advances now enable the development and offer of expanded carrier screening (ECS) in which couples can be screened for several (hundreds of) disorders simultaneously [2,3]. Currently, ECS is mainly offered commercially $[4,5]$.

Many studies have been published about the uptake of testing, knowledge and attitudes of participants, and the (potential) beneficial and harmful aspects of screening for a diversity of disorders, including cystic fibrosis (CF) [6], hemoglobinopathies [7], and fragile-X syndrome [8]. In general, these studies demonstrated that screening is well received by the participants without major adverse psychological effects and showed that the participants intended 
to base their reproductive decisions on the test results [3]. However, these studies mainly focused on screening for one disorder with a relative small proportion of detected carriers and mostly no carrier couples. Few studies have been published about the evaluation of carrier screening for multiple disorders simultaneously $[9,10]$, including studies aimed at individuals of Ashkenazi Jewish descent [10-12]. One study explored the experiences of Australian women who received positive results after prenatal carrier screening on three conditions, showing an essential role of genetic counselors and the importance to improve public awareness in screening programs [13].

In 2012, we started offering preconception carrier screening in an outpatient clinic in a genetically isolated community in the Netherlands [14]. In this founder population, four severe autosomal-recessive disorders occur relatively frequent and are rare outside this village: pontocerebellar hypoplasia type 2 ( $\mathrm{PCH} 2)$, fetal akinesia deformation sequence (FADS), rhizomelic chondrodysplasia punctata type 1, and osteogenesis imperfecta (OI) type IIB/ III. In an evaluation study after 1 year, one-third of the tested individuals was identified as a carrier of at least one of the four disorders, and four carrier couples were identified [14].

This study aimed to evaluate the screening offer for multiple disorders in this genetically isolated Dutch community in terms of participants' knowledge, recall of test results, psychological outcomes, stigmatization, reproductive intentions and decisions, satisfaction, and preferences regarding genetic counseling. The results will provide lessons for the implementation of (future) ECS.

\section{Methods}

To evaluate the preconception carrier screening offer, both attendees and non-attendees of the outpatient clinic were asked to complete questionnaires. Moreover, semistructured interviews with identified carrier couples were performed. The study protocol was approved by the Academic Medical Center (AMC) Medical Ethical Committee in Amsterdam.

\section{Setting}

All individuals originating from the genetically isolated village, who wanted to have children or who were in early pregnancy, were eligible for screening. They were not actively recruited but came to the outpatient clinic on their own initiative or were referred by their General Practitioner (GP), midwife, or gynecologist. The referring health-care providers briefly explained the genetic disorders and the carrier test procedure. Before counseling, which took place in an outpatient clinic in the village or in the university hospital (AMC) Amsterdam, all attendees received an information leaflet, containing information about the four disorders and carrier test procedure, and pretest counseling (Supplementary Information 1). Those who received counseling in the village also were offered a general preconception care consultation by one of the local midwives. Carrier test results were given by phone and all attendees received a letter summarizing the implications of their individual test results. Carrier couples were offered posttest genetic counseling about their reproductive options and an opportunity to speak with a specialized social worker. More details about the outpatient clinic are described elsewhere [14].

\section{Participants and procedure}

\section{Attendees}

Between September 2012 and June 2014, individuals attending the outpatient clinic were asked to complete three questionnaires: approximately 1 week prior to consultation (Q1), within 1 week after consultation (Q2), and 3 months after receiving test results (Q3). In October 2013, an additional number of individuals who did not receive Q1 due to practical reasons were asked to retrospectively complete one questionnaire (Q-retro) 3-14 months (mean 8.5 (SD 2.8) months) after receiving the test results. Q-retro contained a subset of questions of Q1-Q3. Both partners of a couple were asked to complete the questionnaire(s) individually.

\section{Non-attendees}

In December 2014, a questionnaire (Q-non) was sent to 400 individuals of reproductive age (18-40 years) by two GPs to determine reasons for not making an appointment at the outpatient clinic among individuals eligible for carrier screening (i.e., those considering a pregnancy). Exclusion criteria were: suffering from cognitive impairment, being terminally ill, suffering from psychosocial problems, or having fertility problems [15].

\section{Measures}

\section{Questionnaires}

The questionnaires were based on questionnaires previously developed by our multidisciplinary research group for evaluation of carrier screening for $\mathrm{CF}$ and hemoglobinopathies $[7,16-18]$ and were piloted before the start of the study. The questionnaires focused on sociodemographics, familiarity with the specific disorders (two items), reasons for attending/testing (two items), knowledge (six items), 
Table 1 Topics, questions, and answer format of the measures as used in the questionnaires

Topics Questionnaire Questions

\section{Familiarity with disorders}

Familiarity with the disorders

Familiarity with carrier status

\section{Reasons for attending/testing}

Reason(s) for having the carrier test

Familiarity with the carrier test/ outpatient clinic

\section{Knowledge}

Knowledge ${ }^{\mathrm{a}}$

Psychological outcomes and impact

Anxiety (STAI) ${ }^{\mathrm{b}}$

Worry ${ }^{\mathrm{c}}$

Health perception $^{\mathrm{c}}$

Relationship $^{c}$

Stigmatization $^{\mathrm{c}}$

Q1

Q1, Q-retro

\section{Recall of test results}

Recall of test results

Q3, Q-retro

\section{Satisfaction}

Satisfaction

Q3, Q-retro

Q3, Q-retro, Q-non

\section{Preferences regarding genetic counseling}

Necessity pretest consultation

Q2, Q-retro

Genetic counselor ${ }^{\mathrm{c}}$

Q1

Preconception care consultation $\quad$ Q1, Q-retro

\section{Reproductive intentions and decisions}

Pregnancy

Reproductive intentions $^{\mathrm{c}}$

\section{Q1}

Q2

Q2

Q2

Q2
Q-retro

2

I would want to have more information about PGD if my partner and I were both

carriers of the same disorder testing during pregnancy (and not before pregnancy)?)

The results of the carrier test could help me in the future in making decisions about having children

I would not have (anymore) children if my partner and I were both carriers of the same disorder

I would opt for prenatal diagnosis if my partner and I were both carriers of the same disorder

I would consider termination of pregnancy if the unborn child was affected with one of the four disorders 
Table 1 (continued)

\begin{tabular}{lll}
\hline Topics & Questionnaire & Questions \\
\hline Reproductive decisions & Q3, Q-retro & $\begin{array}{l}\text { Did the test results change your ideas about having children? (Yes/No/I don't know. } \\
\text { If yes, why?) } \\
\text { Did you have children after receiving the results of the carrier test or are you/ is your } \\
\text { partner pregnant? }\end{array}$ \\
$\begin{array}{ll}\text { Non-attendees } \\
\text { Non-attendees }\end{array}$ & $\begin{array}{l}\text { Q-non } \\
\text { Are you eligible for an appointment at the outpatient clinic? (If no, why are you not } \\
\text { eligible? If yes, are you planning to make an appointment? If no, why are you not } \\
\text { planning to make an appointment) } \\
\text { Did you do the carrier test?/ Would you like to do the carrier test? }\end{array}$ \\
\hline
\end{tabular}

${ }^{a}$ The number of correct answers was calculated as a sum-score, with a maximum of 6

${ }^{\mathrm{b}}$ Cronbach's $\alpha$ for the STAI scale (Q1) was 0.85

'Items were measured on a 5-point Likert-scale ranging from fully disagree (1) to fully agree (5) and were recoded where necessary

psychological impact (six-item short form of the state scale of the Spielberger Stait-Trait Anxiety Inventory (STAI) [19], worry (two items), health perception (one item), impact of results on couples' relationship (one item), stigmatization (two items)), recall of test results (one item), satisfaction (two items), preferences regarding genetic counseling (three items), and reproductive intentions and decisions (seven items). The questions and answer formats that were used in the questionnaires $(\mathrm{Q} 1-\mathrm{Q} 3$, Q-retro, Qnon) are presented in Table 1 .

\section{Semistructured interviews}

All carrier couples identified between September 2012 and June 2014 were asked to participate in a semistructured interview addressing couples' psychological well-being, reproductive intentions and decisions, and satisfaction. One researcher $(\mathrm{KCAH})$ performed the interviews at the participants' homes.

\section{Data analysis}

Both partners of a couple were treated as independent participants, because earlier research showed that individual partners provide different information [16, 20]. The questionnaires completed by carrier couples were retrospectively excluded from the analysis, because we additionally contacted them for in-depth interviews (data are included in this paper). The answers about the test results were scored as correct or incorrect by comparing them with the participants' actual test results. Five-point Likert-scales were summarized to a three-point scale: (1) (fully) disagree, (2) neither disagree nor agree, and (3) (fully) agree. Participants who did not complete all questions on knowledge (maximum score 6) or STAI (range 20-80) were excluded from these analyses. Friedman's test, followed by a Wilcoxon signed-rank test with Bonferroni correction was used for the analysis of the mean knowledge and STAI scores (Q1-Q3). Differences in knowledge and STAI scores between carrier and non-carriers were analyzed with linear mixed models. Statistical significance was set at $p<0.05$. All analyses were performed using IBM SPSS version 22 for Windows (IBM Corp, Armonk, NY, USA).

Semistructured interviews were audio-taped, transcribed verbatim, and anonymized. Interviews were thematically coded independently by two researchers (IBM and KCAH). Differences in coding were discussed until consensus was reached.

\section{Results}

\section{Outpatient clinic attendees and test results}

Between September 2012 and June 2014, 349 individuals (from 195 couples) received pretest counseling. Of them, 41 individuals visited the outpatient clinic without their partner. All of these 41 individuals and at least 1 person of each couple decided to have the carrier test for all four disorders. In total, $337 / 349(97 \%)$ individuals were tested $(n=12$ were not tested because partner turned out not to be a carrier), of whom $108(32 \%)$ were identified as a carrier of at least one disorder. In total, 8 carrier couples $(4.1 \%$ (8/195 couples)) were identified, facing a 1-in-4 risk of having an affected child with PCH2 $(n=5)$, FADS $(n=2)$, and OI $(n=1)$.

\section{Study response}

Of the 195 couples visiting the outpatient clinic, 127 were asked to participate in the questionnaires (68 in Q1-Q3 and 59 in Q-retro). The response rates of $\mathrm{Q} 1, \mathrm{Q} 2, \mathrm{Q} 3$, and Q-non varied between $75 \%$ and $97 \%$, and the response rate of Q-non was 34\%. Further details are shown in 
Table 2 Sociodemographic characteristics of attendees and non-attendees who completed the questionnaires

\begin{tabular}{|c|c|c|c|}
\hline & $\begin{array}{l}\text { Attendees prospective } \\
\text { (Q1-Q3) } n=110(66 \\
\text { couples) }\end{array}$ & $\begin{array}{l}\text { Attendees retrospective } \\
\text { (Q-retro) } n=72 \text { ( } 47 \\
\text { couples) }\end{array}$ & $\begin{array}{l}\text { Non-attendees } \\
\text { (Q-non) } n=137\end{array}$ \\
\hline Men, $n(\%)$ & $44(40)$ & $26(36)$ & $47(34)$ \\
\hline Women, $n(\%)$ & $66(60)$ & $46(64)$ & $90(66)$ \\
\hline \multicolumn{4}{|l|}{ Age, mean (range) } \\
\hline Men & $32(21-42)$ & $33(22-41)$ & $29(19-40)$ \\
\hline Women & $29(21-40)$ & $29(22-42)$ & $30(18-40)$ \\
\hline \multicolumn{4}{|l|}{ Level of education ${ }^{\mathrm{a}}, n(\%)$} \\
\hline Low & $36(33)$ & $29(40)$ & $32(23)$ \\
\hline Intermediate & $42(38)$ & $25(35)$ & $58(42)$ \\
\hline High & $32(29)$ & $18(25)$ & $47(34)$ \\
\hline \multicolumn{4}{|l|}{ Religiosity, $n(\%)$} \\
\hline $\begin{array}{l}\text { No religion/not actively } \\
\text { religious, } n(\%)\end{array}$ & $79(72)$ & $49(68)$ & $108(79)$ \\
\hline Actively religious, $n(\%)$ & $31(28)$ & $23(32)$ & $29(21)$ \\
\hline Married/cohabiting, n (\%) & $105(95)$ & $71(99)$ & $100(73)$ \\
\hline Having children $^{\mathrm{b}}, n(\%)$ & $52(47)$ & $28(39)$ & $60(44)$ \\
\hline $\begin{array}{l}\text { Couples pregnant at first } \\
\text { visit }^{\mathrm{b}}, n(\%)\end{array}$ & $19(29)$ & $24(51)$ & $12(9)$ \\
\hline $\begin{array}{l}\text { Couples planning children } \\
\text { within } 2 \text { years, } n(\%)\end{array}$ & $22(33)$ & $8(17)$ & NA \\
\hline \multicolumn{4}{|c|}{ Parents originating from the genetically isolated community, $n(\%)$} \\
\hline Both parents & $93(85)$ & $61(85)$ & $106(77)$ \\
\hline One of the parents & $14(13)$ & $11(15)$ & $25(18)$ \\
\hline $\begin{array}{l}\text { Consanguineous couples }{ }^{\mathrm{c}} \text {, } \\
n(\%)\end{array}$ & $2(3)$ & $1(2)$ & NA \\
\hline
\end{tabular}

$N A$ not assessed

${ }^{a}$ Low: primary school, lower level of secondary school, lower vocational training. Intermediate: higher level of secondary school, intermediate vocational training. High: higher vocational training, university

${ }^{\mathrm{b}}$ At first visit for the individuals attending the outpatient clinic (Q1-Q3, Q-retro); At the time of filling in the questionnaire for individuals not attending the outpatient clinic (Q-non)

${ }^{\mathrm{c}}$ Consanguinity is defined here as a union between two individuals who are related as second cousins or closer

Supplementary Table 1 . Seven out of the eight identified carrier couples were interviewed (one couple could not be contacted).

\section{Participants' characteristics}

Sociodemographic characteristics of the questionnaire participants (attendees and non-attendees) are presented in Table 2. Of the 182 test attendees $(\mathrm{Q} 1(n=110)$ and Q-retro $(n=72)), 51(28 \%)$ were carrier of at least one disorder. Ninety-three $(51 \%)$ visited the outpatient clinic in their own village and 89 (49\%) in the university hospital. Overall, $43 \%$ of participants had a family member who is a carrier of or affected by one of the four disorders, and $47 \%$ knew someone outside their family with one of these disorders.

\section{Reasons for attending/testing}

Attendees were informed about the outpatient clinic by friends/colleagues $(49 \%, n=90)$, family members $(44 \%$, $n=80)$, their midwife/gynecologist $(16 \%, n=30)$, media (newspapers/television/radio/internet) $(9 \%, n=17)$, their GP $(8 \%, n=14)$, and/or their partner $(6 \%, n=11)$. The main reason for having the carrier test was to avoid having an affected child (32\%), the severity of the disorders (19\%), perceiving a high risk of being a carrier (14\%), and fear to regret afterwards (7\%) (Supplementary Table 2). Only $17 / 93$ attendees (18\%) in the village accepted the offer for a separate general preconception consultation by one of the local midwives. At pretest counseling, $38 \%$ of the couples were already pregnant. The main reason for not attending before pregnancy was: being unaware of the testing 


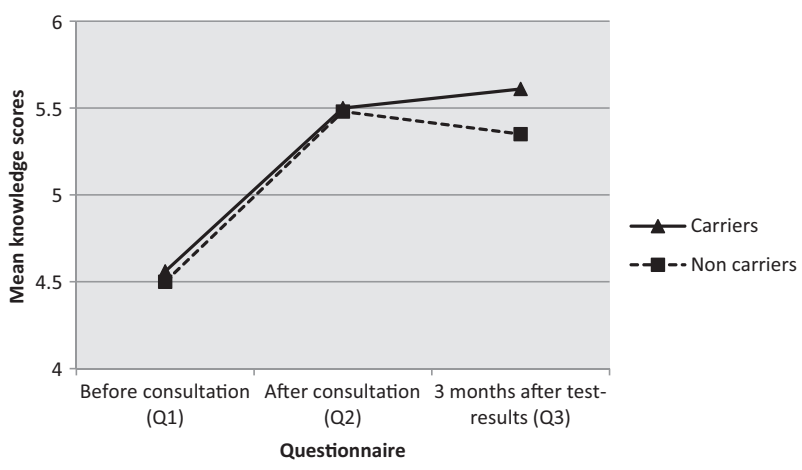

Fig. 1 Mean knowledge scores of attendees who completed all questionnaires $(\mathrm{Q} 1-\mathrm{Q} 3) . \boldsymbol{\Delta}=$ carriers $(n=18) ; \boldsymbol{-}=$ non-carriers $(n=52)$

possibility ( $43 \%, n=27)$, not thinking about the test before $(22 \%, n=14)$, pregnancy-induced worry about having an affected child $(14 \%, n=9)$, only recent identified carrier status in family members/friends $(8 \%, n=5)$, unplanned pregnancy $(8 \%, n=5)$, and other reasons $(5 \%, n=3)$.

\section{Knowledge}

The mean $(M)$ knowledge score among attendees before consultation (4.51; SD 1.52; Q1) significantly increased directly after consultation $(M=5.49$; SD 0.94 ; Q2) $(p<$ $0.001)$, and remained high $(\mathrm{M}=5.41 ; \mathrm{SD} 1.01)$ at 2 months follow-up (Q3). The mean knowledge score of attendees who filled out Q-retro was 5.19 (SD 1.06). Knowledge scores did not differ between carriers (A) and non-carriers (B) $(p=0.85)$ on Q1-Q3 (Fig. 1). Answers to separate knowledge questions are presented in Supplementary Table 3. The question about the chance of having an affected child if both partners were identified as carriers of two different disorders was answered incorrectly by $29 \%$ (Q1), 11\% (Q2), 9\% (Q3), and 14\% (Q-retro).

\section{Recall of test results}

At 3-month follow-up, 97\% of attendees correctly recalled their own test results and the results of their partner. In two couples, one of the partners was carrier of FADS but they reported being carrier of $\mathrm{PCH} 2$. One individual reported that she and her partner had not been tested on FADS, although they were, and turned out not to be carriers. All seven interviewed carrier couples recalled their test results correctly.

\section{Psychological outcomes}

\section{Worry and anxiety}

After receiving the test results, $63 \%$ of 152 attendees reported that they had been feeling worried while waiting

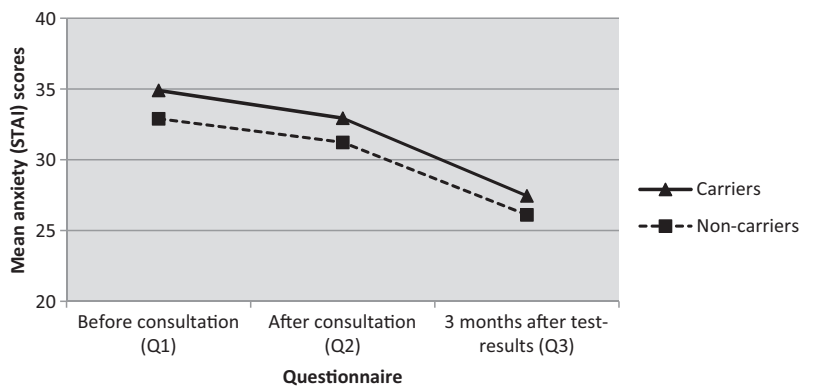

Fig. 2 Mean level of anxiety (assessed by using the six-item short form of the State-Trait Anxiety Inventory [STAI]) [19] among attendees who completed all questionnaires (Q1-Q3). $\mathbf{\wedge}=$ carriers $(n=17) ; \mathbf{\square}=$ non-carriers $(n=54)$

for their test results and $4(3 \%)$ still felt worried afterwards. Mean anxiety score among attendees before consultation (33.38 (SD 10.10; Q1) non-significantly decreased directly after consultation $(M=31.64$; SD 9.43; Q2) $(p=0.10)$, and significantly decreased $(M=26.43 ; \mathrm{SD} 6.53)(p<0.001)$ at 3 months follow-up (Q3). There were no significant differences in STAI scores between carriers and non-carriers $(p=0.98 ;$ Fig. 2$)$

Carrier couples' first reactions on receiving the test results were: shock, panic, sadness, and disappointment (Table 3, quotes \#1 and \#2). Being a carrier appeared to be of minor importance, compared to the impact of being a carrier couple on the more complicated process of having children. Though perceiving the results as a shock, one couple was not planning to have children on the short term and postponed the discussion about it until they did (Table 3, quote \#3).

\section{Health perception}

Two of the 39 carriers (5\%) and none of the carrier couples perceived themselves as less healthy after receiving their test results.

\section{Impact of results on couples' relationship}

Almost all attendees (96\%) perceived no impact of carrier testing on the relationship with their partner. Five out of the six attendees, who perceived a positive influence, reported an increased certainty about having children. No one reported a negative influence on their relationship.

The interviewed carrier couples reported both positive and negative influences on their relationship. They indicated that differences in coping with the results between both partners had a negative influence (Table 3, quote \#4). Others stated that the improvement in communication between both partners positively influences their relationship (Table 3, quote \#5). 
Table 3 Identified themes and representative quotes from the carrier couple interviews $(n=7)$

\section{Number Quote}

Impact of test results

First reaction to test results 1

2 "We were shocked and realized how much luck we have had [with two healthy children]. [...] Winning the lottery... twice." (\#4, woman)

3 "Well, yes, of course it was a shock: what now? But we actually were not being busy with getting children. My family was more worried. We thought: "We'll see." [...] We actually didn't really discuss it until the time we wanted to become pregnant." (\#7, woman)

Relationship

"He was on a very different level than I was. I had a hard time and he hadn't. He doesn't talk about it, so he keeps it inside and I want to throw it all out." (\#2, woman)

$5 \quad$ "You know, you need each other at that time. He was there when I needed him." (\#1, woman)

Stigmatization 6

Reproductive decisions

7 "We don't want to have a child with one of the diseases. Maybe that sounds strange, but such a child is very sick and you know that it will die. [...] You don't want to experience that. That's the worst thing there is, I think. [...] Otherwise it [the child] would have had a lot of misery." (\#3, woman, man)

$8 \quad$ "We wanted to have a second child anyway, so it [the carrier test results] didn't influence our wish to have children. Maybe it will influence our decision for a third child. I think then it's easier to say: "We leave it like this"." (\#2, man)

Reflection and satisfaction

9 "Well, you just let it sink in and afterwards I was happy I knew [the test results], because you can do something about it and you know what to expect and that you can avoid it [the birth of an affected child] in any case. I was very happy with that." (\#3, woman)

10 "Yes, I would do the test again. However the spontaneity in becoming pregnant is gone and sometimes I think: If I had not known it, maybe it had all gone well and you had never thought about anything." (\#5, woman)

11 "I would recommend the test to others, absolutely. You know, what's that one blood sample? I try to persuade them [friends and family members] because I think it's very important." (\#7, woman)

\section{Stigmatization}

Before consultation, three individuals (3\%) (Q1) reported that they would expect that other people would see them differently if they turned out to be a carrier. Overall, $89 \%$ reported that they experienced the carrier test as a privilege. None of the attendees experienced the test as being discriminating. Fear of stigmatization was not an issue for carrier couples. However, one couple thought that other people could see them differently because they are a carrier couple. This couple only informed close relatives because they wanted to protect their future children (Table 3, quote \#6).

\section{Reproductive intentions and decisions}

\section{Non-carrier couples}

Before receiving the test results, $77 \%$ of the attendees believed that the results could help in making decisions about having children. If they were a carrier couple, $93 \%$ would consider PND, and in case of an affected child, 84\% would consider termination of pregnancy. Eighty-one percent would like to have more information about PGD, and $16 \%$ would refrain from having (more) children.

On follow-up (Q3, Q-retro), 16 individuals changed their mind about having children as a consequence of the test results and reported to be more certain about having children. In 8 of these 16 individuals, one partner or both were carrier of one of the disorders but not of the same disorders. On follow-up (Q3), 20\% $(n=23)$ of the couples reported becoming pregnant since the consultation.

\section{Carrier couples}

As a consequence of the results, all interviewed carrier couples wanted to prevent the birth of an affected child and/ or to prevent the child from suffering (Table 3, quote \#7). One couple refrained from having more children while the other six performed PND $(n=5)$ and/ or PGD $(n=2)$. In five pregnancies, the child was unaffected, while three pregnancies with an affected child following prenatal 
Table 4 Main reason of non-attendees $(n=117)$ for not visiting the outpatient clinic

\begin{tabular}{lll}
\hline & $n(\%)$ & \\
\hline Not eligible & $\mathbf{7 5}(\mathbf{6 4})$ & $36(48)$ \\
I do not want to have (more) children & $30(40)$ \\
I do not want to have children yet & $5(7)$ \\
I am/my partner is more than 20 weeks & \\
pregnant & $4(5)$ \\
I am/we are not originating from the & \\
genetically isolated village & \\
Eligible & $\mathbf{4 2 ~ ( 3 6 )}$ \\
$\quad$ Unaware of availability of the outpatient clinic & 22 \\
$\quad$ I am planning to visit the clinic & $16(74)$ \\
$\quad$ I am not pregnant or my partner is not & $1(4)$ \\
pregnant & $1(4)$ \\
$\quad$ I already have healthy children & $1(4)$ \\
$\quad$ It causes worry and anxiety & $3(14)$ \\
$\quad$ No reason & \\
Aware of availability of the outpatient clinic & 20 & $17(85)$ \\
I am planning to visit the clinic & $2(10)$ \\
I am not pregnant or my partner is not & $1(5)$ \\
pregnant &
\end{tabular}

diagnosis were terminated. Two couples decided to have fewer children than originally planned to avoid the risk of having to terminate the pregnancy (Table 3, quote \#8).

\section{Satisfaction}

Attendees were very satisfied about the offer; $97 \%$ would participate if they had to decide again, whereas 5 individuals (2 carriers and 3 non-carriers) were undecided. Overall, 97\% would recommend the screening to other people in the village, whereas five individuals, including one carrier, were undecided. All interviewed carrier couples would have the carrier test if they had to decide again (Table 3, quote \#9). Some mentioned that due to the test, conceiving becomes less spontaneous (Table 3, quote \#10). They were all very explicit in recommending the carrier screening test to other people of the village (Table 3, quote \#11).

\section{Preferences regarding pretest counseling}

The vast majority of attendees (94\%) stated that couples should always have a consultation before testing: to see if people know enough about the test and its consequences $(65 \%, n=106)$, to be able to ask questions $(56 \%, n=92)$, and to hear about other possible risks in pregnancy $(13 \%, n$ $=21)$. The remaining $6 \%(n=11)$ believed that a consultation is not needed as information can also be given by a leaflet $(n=9)$ and/or online $(n=4)$. Only $4 \%(n=4)$ agreed with the statement that "I would rather prefer to have the genetic consultation with my GP than the clinical geneticist"; the others did not agree $(83 \%)$ or were neutral $(13 \%)$.

\section{Non-attendees}

Of the 137 individuals who returned the questionnaire Q-non, 20 had already been tested before. Of the remaining $117,64 \%$ were not eligible for carrier screening (anymore or) at that specific moment, because they did not want to have (more) children (yet) $(n=66)$, were $>20$ weeks pregnant $(n=5)$, or were not originating from the genetically isolated village $(n=4)$ (Table 4$)$. In total, $36 \%(n=$ 42) were eligible for an appointment at the outpatient clinic. Slightly more than half of them $(n=22)$ were unaware of the availability of the clinic, but most (16/22) were planning to visit the clinic in the future now knowing about it. Similarly, the majority of those aware of the clinic (17/20) planned to attend in the future. Three persons did not (plan to) attend, mentioning that they were not pregnant, suggesting that they did not understand correctly that the test preferably is performed preconceptionally.

\section{Discussion}

Individuals who attended the outpatient clinic for carrier screening for four disorders had high knowledge, demonstrated no major psychological outcomes, experienced no stigmatization, and were very satisfied after testing. All identified carrier couples made reproductive decisions based on their test results.

Knowledge increased after counseling and remained high at 3-month follow-up. Still, about 1 in 10 attendees wrongly mentioned an increased risk of having an affected child if both parents are carriers of different disorders. Earlier studies on knowledge in single-disorder carrier screening showed both sustaining of knowledge as well as a decline of knowledge several months after receiving the test results [7, 12]. In one study evaluating carrier screening at Ashkenazi Jewish high schools, it was shown that increasing the number of screened conditions resulted in a decrease in knowledge [12]. Increasing information may-due to 'information overload'-paradoxically undermine rather than enhance knowledge and decision-making [3, 21]. In our study, most attendees could recall their test results correctly, besides two couples who reported being carrier of another disorder than reported to them. Difficulties with recalling test results have been shown in other studies, for example, in an Australian study where some CF carriers falsely believed 
they were only very likely to be carriers [22]. It can be expected that, when expanding the number of disorders screened for and more carriers being identified, recall of test results will become more difficult and thus requires explicit attention in information provision and counseling.

Two-thirds of the attendees felt worried while waiting for their test results. This is higher than reported in studies about screening for one disorder ( $\mathrm{CF}$, hemoglobinopathies) in the general population, for example, by Lakeman et al. [7], and may be explained by the high familiarity with the diseases and the high risk of being a carrier (couple) in this population. Levels of anxiety decreased after receiving reassuring test results, and no difference was present between carriers and non-carriers. Only two of the carriers, and none of the carrier couples, perceived themselves as less healthy after receiving the test results. In a Dutch study on CF carrier screening, it was shown that $7 / 17$ carriers reported feeling less healthy [17]. While it has been shown that increasing the number of screened conditions resulted in an increase in anticipated negative feelings if found to be a carrier [12], it is possible that as carrier screening becomes more common, as is the case in this community, individuals will realize that everyone is a carrier of at least one disease, which may decrease anxiety [3]. From our study in the genetically isolated population, we have no indications that screening for multiple disorders will cause major adverse psychological effects related to anxiety, health perception, and relationship.

One of the supposed advantages of ECS for multiple disorders simultaneously is that it reduces the chance of stigmatization as it allows testing regardless of ancestry [23]. In this genetically isolated community, however, this was not found to be a recognizable concern. Attendees did not report major feelings of stigmatization because of the communitybased type of carrier screening or because of a positive carrier status. Concerns about stigmatization of (presumed) carriers within the community have nevertheless been described, for example, in the carrier testing program 'Dor Yeshorim' in the ultra-orthodox Jewish community [24].

A large percentage of women (38\%) were already pregnant when visiting our outpatient clinic. This was mostly because they were unaware of the availability of testing or they did not think about testing before pregnancy. Besides, only a minority of couples accepted the offer of an additional general preconception care consultation. Although carrier screening is preferably done before pregnancy (preconception), as more reproductive options are available besides prenatal diagnosis [25], it has been acknowledged that it is challenging to reach the target population (couples planning a pregnancy) [18]. Three nonattendants falsely believed that the carrier test can only be performed during pregnancy. In a qualitative interview study among pregnant women with positive ECS results, carrier screening was also confused with other prenatal screening tests [9].

Most attendees were informed about the existence of the carrier screening and the outpatient clinic by close influencers (family/friends). This was also seen in a Jewish genetic disorder screening program [26] and in a Canadian founder population [10]. When introducing ECS in a community, it might be worthwhile to use these influencers to raise awareness about the screening test offer. As we have previously shown [15], when implementing ECS for the general population, the stimulating role of community support is less evident as there is no specific community with which people can identify themselves. Effort should thus be made to increase awareness.

In our study, the vast majority of attendees stated that couples should always have pretest consultation and did not prefer a GP over a genetic counselor. In a focus group study with 40 US genetics professionals, there was consensus that ECS should be accompanied by pretest and posttest genetic counseling, preferably by a clinician with expertise in communicating genetic information [27]. In a Dutch online survey, most potential users of ECS also preferred face-toface consultation but the majority preferred the test to be offered via their GP, probably due to the strong primary care structure in the Netherlands [28]. In this genetically isolated village, counseling of about 200 individuals a year is achievable, when considering a nation-wide population screening program, face-to-face counseling with a genetic counselor is impractical because there are not enough genetic professionals [2]. More personalized information, using, for instance, interactive computerized information/ apps and easily accessible telephone contact with a genetic professional, could be a solution [3]. Furthermore, it is important that genetic counselors inform general practitioners and midwives about all aspects of the carrier screening to raise awareness of the screening offer and to be able to provide couples with information and support preand post-counseling.

The present study has some limitations. First, although the response rates to the questionnaires were very high, not all attendees were asked to participate due to practical reasons. Second, the retrospective questionnaire (Q-retro) may have diluted the clarity of the results, for example, due to recall bias. We have decided to include this questionnaire to learn as much as possible from the participants' experiences. Finally, the study was conducted in one specific genetically isolated population, and the results may therefore not be generalizable to other genetically isolated populations or to the general population.

To conclude, an offer of carrier screening for specific multiple disorders simultaneously in a Dutch founder population was valued as positive and individuals who 
attended the carrier screening were very satisfied. Although this study was conducted in a genetically isolated village, and the results are not representative for other populations/ countries, our experiences can be helpful for the implementation of carrier screening for multiple disorders in other genetically isolated populations and of ECS in the general population. Important in this context is that we have found no evidence that screening for multiple disorders will cause major adverse psychological effects. Moreover, the recall and interpretation of test results may become more challenging for participants in multiple disorder carrier screening, which requires explicit attention in information provision and counseling.

Acknowledgements We thank all participants who took part in the study. General practitioners and midwives are acknowledged for their help in data collection.

Funding Part of this research is funded by the Netherlands Organization for Health Research and Development (ZonMw grant no. 209040001) and is embedded in the Regional Perinatal Network Northwest Netherlands.

\section{Compliance with ethical standards}

Conflict of interests All authors are affiliated to a hospital that offers ECS in a non-commercial setting.

\section{References}

1. Metcalfe SA. Carrier screening in preconception consultation in primary care. J Community Genet. 2012;3:193-203.

2. Edwards JG, Feldman G, Goldberg J, et al. Expanded carrier screening in reproductive medicine-points to consider: a joint statement of the American College of Medical Genetics and Genomics, American College of Obstetricians and Gynecologists, National Society of Genetic Counselors, Perinatal Quality Foundation, and Society for Maternal-Fetal Medicine. Obstet Gynecol. 2015;125:653-62.

3. Henneman L, Borry P, Chokoshvili D, et al. Responsible implementation of expanded carrier screening. Eur J Hum Genet. 2016;24:e1-e12.

4. Borry P, Henneman L, Lakeman P, ten Kate LP, Cornel MC, Howard HC. Preconceptional genetic carrier testing and the commercial offer directly-to-consumers. Hum Reprod. 2011;26:972-7.

5. Lazarin GA, Haque IS, Nazareth S, et al. An empirical estimate of carrier frequencies for $400+$ causal Mendelian variants: results from an ethnically diverse clinical sample of 23,453 individuals. Genet Med. 2013;15:178-86.

6. Ioannou L, McClaren BJ, Massie J, et al. Population-based carrier screening for cystic fibrosis: a systematic review of 23 years of research. Genet Med. 2014;16:207-16.

7. Lakeman P, Plass AM, Henneman L, Bezemer PD, Cornel MC, ten Kate LP. Three-month follow-up of Western and non-Western participants in a study on preconceptional ancestry-based carrier couple screening for cystic fibrosis and hemoglobinopathies in the Netherlands. Genet Med. 2008;10:820-30.

8. Anido A, Carlson LM, Sherman SL. Attitudes toward fragile X mutation carrier testing from women identified in a general population survey. J Genet Couns. 2007;16:97-104.
9. Rothwell E, Johnson E, Mathiesen A, et al. Experiences among women with positive prenatal expanded carrier screening results. J Genet Couns. 2016;26:690-6.

10. Eng CM, Schechter C, Robinowitz J, et al Prenatal genetic carrier testing using triple disease screening. JAMA. 1997;278:1268-72.

11. Warsch JR, Warsch S, Herman E, et al Knowledge, attitudes, and barriers to carrier screening for the Ashkenazi Jewish panel: a Florida experience: education and barriers assessment for Jewish genetic diseases. J Community Genet. 2014;5:223-31.

12. Ioannou L, Massie J, Lewis S, et al Evaluation of a multi-disease carrier screening programme in Ashkenazi Jewish high schools. Clin Genet. 2010;78:21-31.

13. Beard CA, Amor DJ, Di PL, Archibald AD. "I'm healthy, it's not going to be me": exploring experiences of carriers identified through a population reproductive genetic carrier screening panel in Australia. Am J Med Genet A. 2016;170:2052-9.

14. Mathijssen IB, Henneman L, van Eeten-Nijman JM, et al. Targeted carrier screening for four recessive disorders: high detection rate within a founder population. Eur $\mathrm{J}$ Med Genet. 2015;58:123-8.

15. Holtkamp KC, Mathijssen IB, Lakeman P, et al. Factors for successful implementation of population-based expanded carrier screening: learning from existing initiatives. Eur J Public Health. 2016;27:372-7.

16. Henneman L, Bramsen I, van der Ploeg HM, et al. Participation in preconceptional carrier couple screening: characteristics, attitudes, and knowledge of both partners. J Med Genet. 2001;38:695-703.

17. Henneman L, Bramsen I, van der Ploeg HM, ten Kate LP. Preconception cystic fibrosis carrier couple screening: impact, understanding, and satisfaction. Genet Test. 2002;6:195-202.

18. Lakeman P, Plass AM, Henneman L, Bezemer PD, Cornel MC, ten Kate LP. Preconceptional ancestry-based carrier couple screening for cystic fibrosis and haemoglobinopathies: what determines the intention to participate or not and actual participation? Eur J Hum Genet. 2009;17:999-1009.

19. Marteau TM, Bekker $H$. The development of a six-item short-form of the state scale of the Spielberger State-Trait Anxiety Inventory (STAI). Br J Clin Psychol. 1992;31(Pt 3):301-6.

20. Poppelaars FA, Henneman L, Ader HJ, et al. Preconceptional cystic fibrosis carrier screening: attitudes and intentions of the target population. Genet Test. 2004;8:80-89.

21. Schwartz B. The paradox of choice: why more is less. New York, NY, USA: Harper Collins Publishers; 2004.

22. Gordon C, Walpole I, Zubrick SR, Bower C. Population screening for cystic fibrosis: knowledge and emotional consequences 18 months later. Am J Med Genet A. 2003;120A:199-208.

23. Van der Hout S, Holtkamp KC, Henneman L, de Wert G, Dondorp WJ. Advantages of expanded universal carrier screening: what is at stake? Eur J Hum Genet. 2016;25:17-21.

24. Raz AE, Vizner Y. Carrier matching and collective socialization in community genetics: Dor Yeshorim and the reinforcement of stigma. Soc Sci Med. 2008;67:1361-9.

25. De Wert GM, Dondorp WJ, Knoppers BM. Preconception care and genetic risk: ethical issues. $\mathbf{J}$ Community Genet. 2012;3:221-8.

26. Shao Y, Liu S, Grinzaid K. Evaluation of two-year Jewish genetic disease screening program in Atlanta: insight into community genetic screening approaches. J Community Genet. 2015;6:137-45.

27. Cho D, McGowan ML, Metcalfe J, Sharp RR. Expanded carrier screening in reproductive healthcare: perspectives from genetics professionals. Hum Reprod. 2013;28:1725-30.

28. Plantinga M, Birnie E, Abbott KM, et al. Population-based preconception carrier screening: how potential users from the general population view a test for 50 serious diseases. Eur J Hum Genet. 2016;24:1417-23. 